\title{
SURGICAL TREATMENT OF TONGUE BASE CARCINOMA USING UPPER LATERAL PHARYNGOTOMY
}

\author{
Tsvetan Tonchev, Savina Nencheva \\ Department of Oral and Maxillofacial Surgery, Faculty of Dental Medicine, \\ Prof. Paraskev Stojanov Medical University of Varna, Bulgaria
}

\begin{abstract}
:
The patients with tongue base carcinoma are usually diagnosed in an advanced stage of the disease. The authors present a retrospective analysis of four patients treated in the period 2006-2008 using the method of upper lateral pharyngotomy in order to remove the tumor. On the basis of the preoperative evaluation two of the patients had ipsilateral neck dissection. The authors report the survival rate giving the account of the combined treatment and the necessity of extra procedures. The article describes the operative techniques and the important moments of making a decision. A review of the literature concerning this matter has been made.
\end{abstract}

Key words: Tongue base carcinoma; Approach; Surgical treatment; Upper lateral pharyngotomy.

\section{INTRODUCTION}

Tongue base carcinoma is an aggressive tumor with bad prognosis. ${ }^{12}$ Its optimal treatment is disputable. The defenders of radiation therapy as a method of first choice, argument themselves with the high degree of local control and with better long term functional results, regarding the speech and swallowing, in a result of preserved anatomical structures. ${ }^{17}$ The supporters of the surgical treatment contend the fact that with surgical treatment important histological information is acquired which may be used for further definition of the treatment process and adjuvant therapy. The regional control when using surgical treatment is almost $100 \%$, while when unsuccessful the radiation therapy decreases the chance for favorable outcome after surgical treatment. ${ }^{4,}{ }^{14}$ Essential improvement of the local control is marked when the treatment is combined: surgical plus postoperative radiation, and recently there are integrated programs for multimodal treatment with personalized treatment plan. ${ }^{10,11,13,16}$

\section{MATERIALS AND METHODS}

The authors present retrospective analysis of four patients with tongue base carcinoma operated in the period 2006-2008 using surgical approach through lateral pharyngotomy and removing the tumor (Fig. 1-3).

Fig. 1. Clinical cases with tongue base carcinoma

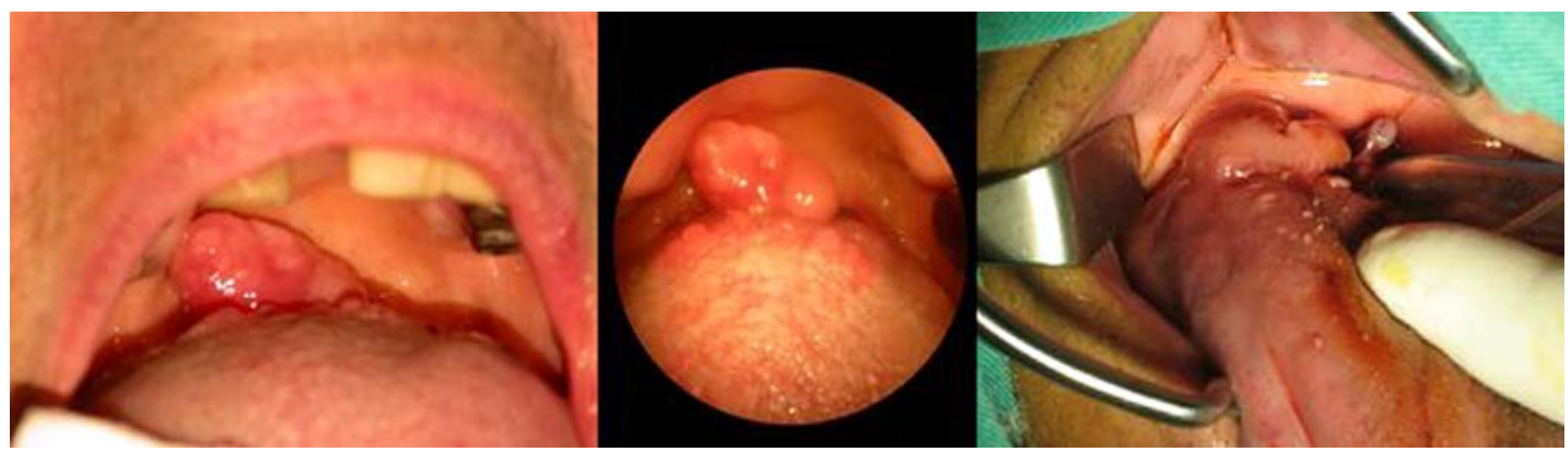


Fig. 2. Surgical approach to the base of tongue (according to B. Baily ${ }^{3}$ )

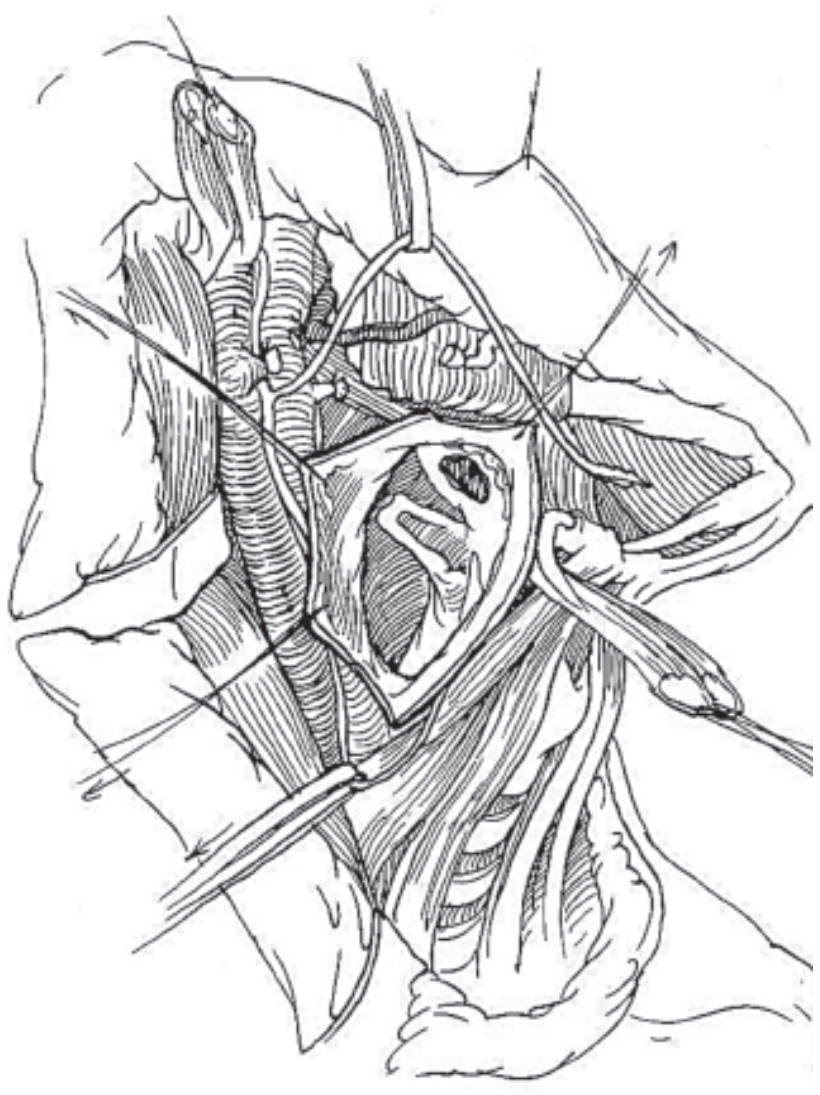

Fig. 3. Intraoperative view in our case

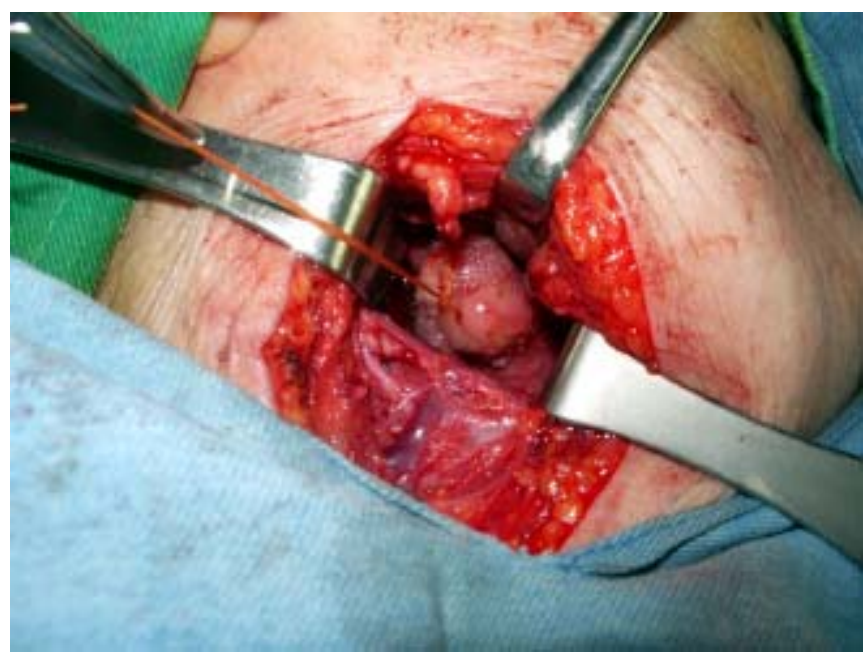

The average age of the patients is 68,5 years (between 56 and 77). Three of them are male and one female. On the basis of the clinical finding and the tests made the patients were staged in accordance with the criteria of the American Joint Committee on Cancer. ${ }^{2}$ At admission two of the patients were with enlarged lymph nodes of the neck which determined stage III and IVA of the disease. After xray there was no evidence for clinically notable metastasis (Tab. 1). The lab blood tests were in norm.

\begin{tabular}{|l|c|c|c|c|c|c|}
\hline № & $\begin{array}{c}\text { Age } \\
\text { stage }\end{array}$ & Sex & T & N & M & Clinical \\
\hline $\mathbf{1 .}$ & 56 & $\mathrm{M}$ & 1 & 1 & 0 & III \\
\hline $\mathbf{2 .}$ & 68 & $\mathrm{M}$ & 1 & 2 & 0 & IVA \\
\hline $\mathbf{3 .}$ & 73 & $\mathrm{M}$ & 1 & 0 & 0 & $\mathrm{I}$ \\
\hline $\mathbf{4 .}$ & 78 & $\mathrm{~F}$ & 1 & 0 & 0 & $\mathrm{I}$ \\
\hline
\end{tabular}

Tab. 1. Distribution of patients by age, sex and TNM criteria

All the patients underwent surgical resection of the primal tumor using approach through upper lateral pharyngotomy and with two of them the method was combined with ipsilateral neck dissection during the same operation (Tab. 2). After interdisciplinary discussion all of the patients underwent postoperative radiation therapy.

\begin{tabular}{|l|c|c|c|c|c|}
\hline № & $\begin{array}{c}\text { Surgical } \\
\text { treatment }\end{array}$ & $\begin{array}{c}\text { Histological } \\
\text { result }\end{array}$ & $\begin{array}{c}\text { Compli- } \\
\text { cation }\end{array}$ & $\begin{array}{c}\text { Follow up } \\
\text { (months) }\end{array}$ & Status \\
\hline 1. & TR+RND & SCC & No & 18 & DOD \\
\hline 2. & TR+RND & SCC & No & 9 & DPD \\
\hline 3. & TR & SCC & No & 25 & A \\
\hline 4. & TR & SCC & No & 10 & A \\
\hline
\end{tabular}

Tab. 2. Surgical treatment modalities, results and survival in our patients

(Abbreviations: TR - tumor resection; RND - radical neck dissection; SCC - squamous cell carcinoma; DOD death from other disease; DPD - death from progression of the disease)

\section{RESULTS}

In the early postoperative period there were no notable complications of systemic or local character. The patients have been put naso-gastric tube preoperatively which was removed 5 days after surgery when the capability for swallowing was available. None of the patients had serious disturbances in the breathing process that would force the need of tracheotomy. The follow-up period is between 9 and 25 months (15,5 average). To the present moment two of the patients are alive; one is deceased from different cause, not related with oncological disease, and one has died as a result of progression of the main oncological disease. The last patient was determined with local persistence of the tumor process and the development of distant metastasis four months after surgery. 


\section{DISCUSSION}

The principles of tongue base carcinoma treatment undergo heterogeneous development over the last few years. The successful treatment is complicated by the fact that most of the cases with such tumors are usually without symptoms until relatively late stage, which leads to prevail over much advanced cases with high frequency of neck metastasis. Although the progress of the therapeutic strategies and the improved opportunities for local control the overall survival rate has not increased much. The data regarding the use of operative treatment alone are few. The retrospective analysis shows that few are the patients that have been directed at an early stage of the disease, while the patients in advanced stage are usually treated with radiation therapy. With the surgical treatment the local control of the primal lesions at an early stage is between $74 \%$ and $100 \%$, while with patients in advanced stage is between $22 \%$ and $27 \% .^{5}, 6,13,15-17$ The fact was also confirmed by our results. The regional control varies between $89 \%$ and $100 \%$ for No, from $50 \%$ to $75 \%$ for N1 and less than $50 \%$ for $\mathrm{N} 2 .{ }^{6,13}$ The combination of resection of the tumor and neck dissection when needed and postoperative radiation therapy is proven to increase the degree of local control compared with the separate application of one of the two methods. ${ }^{8,10,14,17}$ The functional results after surgical treatment are considerably worsened depending on the size of the primal tumor, due to the radical resection of the tumor mass and may lead to irreversible functional disorders. Although the improved regional control of the disease most of the patients die as a result of distant metastasis, developing in $13-16 \%$ of the cases, as particularly high risk are the cases with advanced local process and regional metastasis. . $^{1,6,7,9,11,13,17}$

\section{CONCLUSION}

The interdisciplinary approach has been forced at the up-to-date treatment of tongue base carcinoma. The decision for every single case has been evaluated depending on the overall condition of the patient and the stage of the disease. Through combined surgical and radiation therapy the results are much improved in the early stages while for advanced cases the results of the combination are disputable.

\section{BIBLIOGRAPHY}

1. Alvi A, J. Johnson. Development of distant metastasis after treatment of advanced-stage head and neck cancer. Head Neck 1997;19:500-505.

2. American Joint Committee on Cancer: Pharynx (including base of tongue, soft palate, and uvula). In: AJCC Cancer Staging Atlas. Greene, F, Compton, C, Fritz, A, Shah, J, Winchester D, editors. New York; Springer; 2006: 27-40.

3. Baily B, Surgey for cancer $\left(\mathrm{T}_{1}\right.$ and $\mathrm{T}_{2}$ ) of the midline tongue base. In: Surgery of the oral cavity. Chicago; Year book medical publishers; 1989:67.

4. Calais G, et al. Squamous cell carcinoma of the base of the tongue: results of treatment in 115 cases. Br J Radiol 1989;62:849-853.

5. Dupont J, O. Guillamondegui, R. Jesse. Surgical treatment of advanced carcinomas of the base of the tongue. Am J Surg 1978;136:501-503.

6 . Foote R, et al. Base of tongue carcinoma: patterns of failure and predictors of recurrence after surgery alone.
Head Neck 1993;15:300-307.

7. Gourin C, J. Johnson, Surgical treatment of squamous cell carcinoma of the base of tongue. Head Neck. 2001; 23(8):653-60.

8. Hinerman R, et al. External beam irradiation alone or combined with neck dissection for base of tongue carcinoma: an alternative to primary surgery. Laryngoscope 1994;104:1466-1470.

9. Jaulerry C, et al. Results of radiation therapy in carcinoma of the base of the tongue. Cancer 1991;67:1532-1538.

10. Lee $\mathrm{H}$, et al. Long-term regional control after radiation therapy and neck dissection for base of tongue carcinoma. Int J Radiat Oncol Biol Phys 1997;38:9951000 .

11. Machtay $M$, et al. Combined surgery and postoperative radiotherapy for carcinoma of the base of tongue: analysis of treatment outcome and prognostic value of margin status. Head Neck 1997;19:494499.

12. Mark A, et al. Functional Outcomes
After Treatment of Squamous Cell Carcinoma of the Base of the Tongue. Arch Otolaryngol Head Neck Surg. 2002;128:887-891.

13. Nisi K, et al. Adjuvant radiotherapy for squamous cell carcinoma of the tongue base: improved local-regional disease control compared with surgery alone. International J Radiat Oncol Biol Phys 1998; 41:371-377.

14. Parsons J, R. Million, N. Cassisi. Carcinoma of the base of tongue: results of radical irradiation with surgery reserved for irradiation failure. Laryngoscope 1982;92:689-696.

15. Spiro R, Strong E. Surgical treatment of cancer of the tongue. Surg Clin North Am 1074;54:759-765.

16. Weber P, Myers E, Johnson J. Squamous cell carcinoma of the base of tongue. Eur Arch Oto-rhino-laryngol 1993;250:63-68.

17. Weber R, et al. Treatment selection for carcinoma of the base of tongue. Am J Surg 1990;160:415-419.

\section{Corresponding author:}

Dr. Tsvetan Tonchev, DMD, PhD

Department of Oral and Maxillofacial Surgery, Faculty of Dental Medicine;

Prof. Paraskev Stojanov Medical University of Varna

55 Marin Drinov street, BG-9002 Varna, Bulgaria

E-mail: mfstonchev@mu-varna.bg 